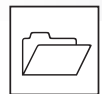

Endokrynologia Polska

DOI: 10.5603/EP.a2020.0047

Volume/Tom 71; Number/Numer 5/2020

ISSN 0423-104X

\title{
When you hear hooves, you should look for... zebras
}

\author{
Elżbieta A. Zych ${ }^{\circledR 1}$, tukasz P. Obołończyk ${ }^{\circledR 1}$, Tomasz K. Gorycki ${ }^{\circledR 2}{ }^{2}$, Krzysztof Sworczak ${ }^{\circledR 1}$ \\ ${ }^{1}$ Department of Endocrinology and Internal Medicine, Medical University of Gdańsk, Gdańsk, Poland \\ ${ }^{2}$ Department of Radiology, Medical University of Gdańsk, Gdańsk, Poland
}

Key words: goitre; hypothyroidism; amyloidosis

In 2005 a 21-year-old Caucasian woman diagnosed with hyperimmunoglobulinaemia $\mathrm{D}$ and periodic fever syndrome (HIDS), hypothyroidism, adrenal insufficiency, chronic hepatitis $\mathrm{C}$, and chronic kidney disease (post kidney transplant due to renal amyloidosis) presented with goitre. The patient was previously treated with radioiodine twice (in 2001 and 2002) with no significant improvement regarding thyroid volume. The aim of this course of treatment was to reduce thyroid volume

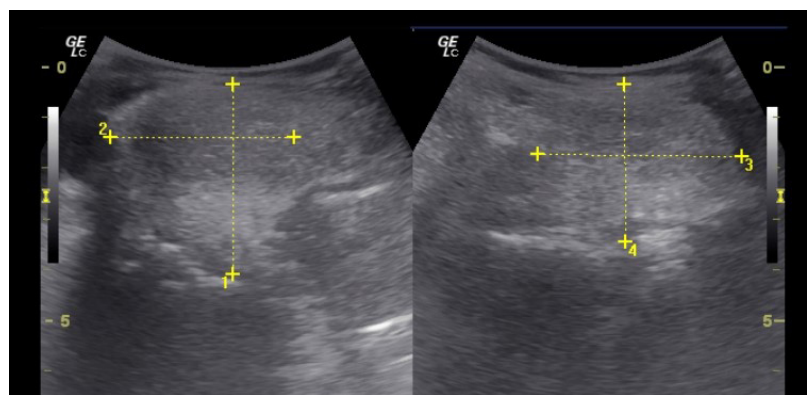

Figure 1. Thyroid ultrasound - notice blurred gland margins and non-homogeneous, mostly hyperechoic tissue

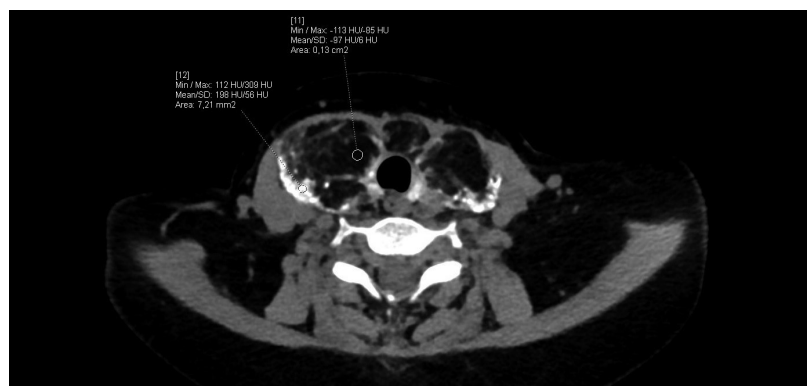

Figure 2. A CT scan of the neck - notice hypodense amyloid masses filling most of the thyroid and well-demarcated calcifications (predominantly peripheral) because the patient declined surgery. Anti-thyroid antibodies were negative, and she was not hyperthyroid at that time. Fine needle aspiration biopsy (FNAB) was inconclusive.

Thyroid ultrasound (Fig. 1) was performed and revealed surprisingly non-homogeneous, mostly hyperechoic tissue with blurred gland margins.

A CT scan of the neck (Fig. 2) revealed hypodense masses filling most of the capacity of both thyroid lobes and isthmus. Well-demarcated calcifications (predominantly peripheral) were present. There was no significant lateralisation of the trachea. Mass effect was slightly more pronounced on the right side. Figure 3 shows a reconstruction of the thyroid with volumetric analysis of the lobes. Thyroid volume at the time of the CT scan was $152 \mathrm{~mL}$.

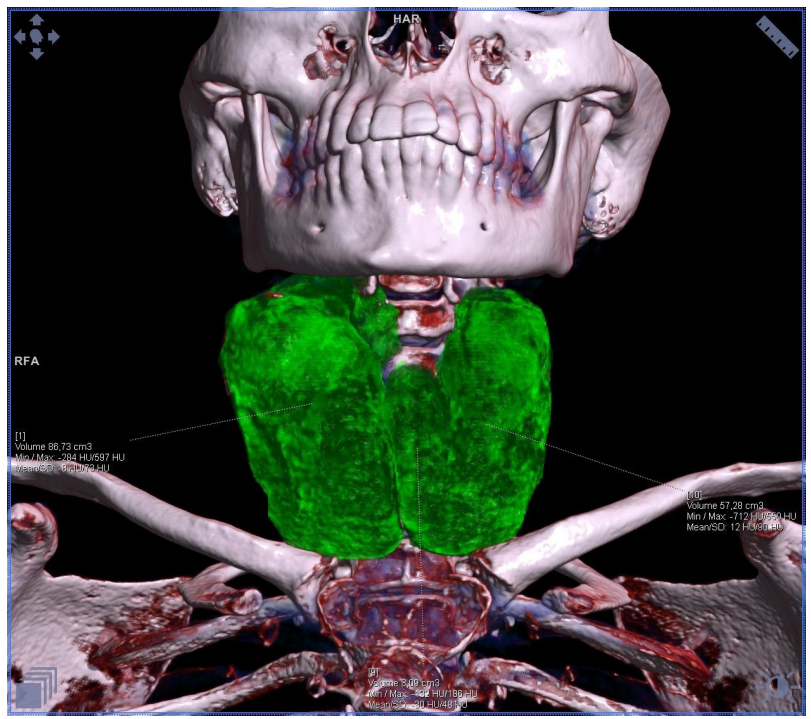

Figure 3. A CT scan of the neck with reconstruction of the thyroid and volumetric analysis of the lobes 
Fine needle aspiration biopsy was repeated, and positive Congo staining finally established the diagnosis as amyloid goitre secondary to HIDS.

The deposition of amyloid in the thyroid is more commonly observed in patients diagnosed with secondary amyloidosis than in those with primary amyloidosis [1].

While the presence of amyloid in the thyroid in the course of amyloidosis is not uncommon, the accumulation is rarely pronounced enough to cause clinically apparent enlargement of the gland [1].

Amyloidosis is a complication of hereditary periodic fever syndromes, particularly FMF (Familial Mediterranean Fever). Systemic amyloidosis occurred in 7.6\% of FMF patients studied in Turkey, while only $0.27 \%$ developed amyloid goitre [2].

The incidence of amyloidosis secondary to HIDS is low - only six cases have been described [3].

\section{Grants and other funding sources}

None declared.

\section{Acknowledgements}

N/A.

\section{Conflict of interest}

None declared.

\section{References}

1. Yildiz L, Kefeli M, Kose B, et al. Amyloid goiter: two cases and a review of the literature. Ann Saudi Med. 2009; 29(2): 138-141, doi: 10.4103/0256-4947.51808, indexed in Pubmed: 19318742.

2. Ciğerli O, Unal AD, Parıldar H, et al. Amyloid goiter due to familial mediterranean Fever in a patient with byler syndrome: a case report. Balkan Med J. 2014; 31(3): 261-263, doi: 10.5152/balkanmedj.2014.13111, indexed in Pubmed: 25337425.

3. Kallianidis AF, Ray A, Goudkade D, et al. Amyloid A amyloidosis secondary to hyper IgD syndrome and response to IL-1 blockage therapy. Neth J Med. 2016; 74(1): 43-46, indexed in Pubmed: 26819362 